\title{
OS NOVOS OLIMPIANOS: O PODER CULTURAL SOB A ÓTICA DE EDGAR MORIN
}

\author{
THE NEW OLYMPIANS: \\ CULTURAL POWER UNDER THE OPTICS OF EDGAR MORIN
}

\begin{abstract}
(iD) Franthiesco Ballerini
Doutorando do Programa de Pós-Graduação em Comunicação Social Bolsista Prosuc/Capes para projetos Interdisciplinares/Multidisciplinares

Universidade Metodista de São Paulo - UMESP

franthiesco@yahoo.com.br
\end{abstract}

\begin{abstract}
Izabel Petraglia
Doutora em Educação pela USP com Pós-Doutorado pelo Centre Edgar Morin - EHESS/CNRS - Paris - France Professora Titular do Programa de Pós-Graduação em Educação Universidade Metodista de São Paulo - UMESP izabelpetraglia@terra.com.br
\end{abstract}

Resumo: Este artigo tem por objetivo refletir sobre as contribuições do pensamento do sociólogo francês Edgar Morin acerca da cultura de massa para o entendimento do conceito de "poder cultural". Poder cultural é o entrelaçamento do conceito de "poder simbólico", desenvolvido pelo também sociólogo francês Pierre Bourdieu, com o conceito de "poder suave" (soft power), do cientista político norte-americano Joseph Nye. Artistas e produtores detentores de poder cultural são capazes de influenciar, seduzir e mobilizar multidões ao redor do mundo com suas obras, causas, aparência e, claro, produtos da indústria cultural. De que forma as ideias de Edgar Morin, desde a cultura de massa até o conceito de "olimpianos", podem elucidar os caminhos de aquisição do poder cultural? A partir da hermenêutica de profundidade, chega-se à conclusão de que, por meio da educação, é possível entender estes mecanismos de consolidação do poder cultural, o que é um passo fundamental para reverter a lógica que dá muito poder a poucos artistas enquanto torna invisíveis muitos outros.

Palavras-chave: poder cultural; Edgar Morin; poder suave; educação.

\begin{abstract}
This article aims to reflect about the contributions of the work of the French sociologist Edgar Morin about mass culture for the comprehension of the concept of "cultural power". Cultural power is the interlacement of the concept of "symbolic power", developed by the also French sociologist Pierre Bourdieu, with the concept of "soft power", of the American political scientist Joseph Nye. Artists and producers who have cultural power are able to influence, seduce and mobilize multitudes around the world with their art, causes, appearances and, of course, products of the cultural industry. How the ideas of Edgar Morin, from mass culture to the concept of "olympians", contribute to elucidate the ways to acquire cultural power? From the depth hermeneutics the conclusion is that, by education, it's possible to understand the mechanisms of consolidation of cultural power, which is a fundamental step to reverse the logic that gives power to very few artists while makes many other invisible.
\end{abstract}

Keywords: cultural power. Edgar Morin. soft power. education.

\section{Para citar - ABNT NBR 6023:2018}

BALLERINI, Franthiesco; PETRAGLIA, Izabel. Os novos olimpianos: o poder cultural sob a ótica de Edgar Morin. Cadernos de Pós-graduação, São Paulo, v. 20, n. 1, p. 39-52, jan./jun. 2021. Disponível em: https://doi.org/10.5585/cpg.v20n1.19824. 
Introdução

A humanidade exerce poder das mais variadas formas há séculos, moldando as civilizações, o planeta e o futuro da própria espécie. Quando um presidente da República autoriza um auxílio emergencial aos mais pobres, está exercendo o poder político dentro do país que lhe atribuiu, por meio de eleições, este poder. Se um líder muçulmano reúne milhares de pessoas, que se submetem a dias de jejum por conta de alguma crença, ele está exercendo poder religioso sobre elas. O poder também emana de campos como a ciência. A legitimidade da palavra do médico Dráuzio Varella, por exemplo, é capaz de influenciar milhares de pessoas a utilizarem máscaras em períodos como o da pandemia da Covid-19, nos anos de 2020 e 2021, no Brasil.

A cultura é também, há séculos, uma fonte imensa de poder para pessoas, nações, instituições e empresas do mundo inteiro. Filmes são capazes de impulsionar manifestações pelo fim de guerras, pelos direitos das mulheres, dos negros. Músicas tornam-se hinos de protesto contra governos repressivos. Quadros, como o do artista Banksy, se autotrituram em pleno leilão como forma de protesto contra a mercantilização da arte, valorizando ainda mais o passe do próprio artista (NANAY, 2018). O Prêmio Nobel de Literatura de Pablo Neruda transforma cidades, como Valparaíso, no Chile, em destinos turísticos internacionais (CASA..., 2017). A cultura, portanto, exerce um poder fascinante e em escala global.

Este artigo tem como objetivo compreender como a cultura se transforma em instrumento de poder, à luz das reflexões de Edgar Morin acerca de temas envolvendo o cinema e a comunicação de massa, utilizando como método a hermenêutica da profundidade, que contribui para o entendimento de formas simbólicas, produzidas em determinados momentos e contextos históricos, os quais influenciam o seu desenvolvimento (MOURA; ALMEIDA, 2017).

O pensamento de Morin, especialmente quando reflete a cultura sob a ótica da educação, ilumina consideravelmente o conceito de "poder cultural" aqui proposto, fruto do entrelaçamento dos conceitos de "poder simbólico", de Pierre Bourdieu, e "poder suave" (soft power), de Joseph Nye. O poder cultural é consolidado aos poucos, oferece inegável vantagem a alguns artistas diante da invisibilidade de muitos outros. Este artigo objetiva, portanto, contribuir para a compreensão destes mecanismos, de forma a iniciar, por vias da educação e dos hábitos de consumo cultural, mudanças para caminhos mais democráticos na distribuição do poder.

\section{Edgar Morin e o poder cultural}

O sociólogo francês Edgar Morin dedicou parte de sua obra ao entendimento da cultura de massa que, nas palavras de seu conterrâneo Éric Macé - sociólogo e especialista em movimentos culturais, mídia, cultura de massa -, pode não fazer parte do imaginário de todo o mundo, mas 
certamente se constitui em um "imaginário conhecido de todos" (MACÉ, 2018, p. XXI). Isso ocorre a partir do século XX, a época de Espírito do Tempo, título da obra de Morin (2018), da qual Macé escreve o preâmbulo.

Entendemos por cultura de massa aquela que é produzida para o consumo de grande quantidade de pessoas, seguindo padrões industriais e sendo alvo da cobertura jornalística dos grandes veículos de comunicação mundiais. A título de exemplo, o lançamento de filmes pelas produtoras, que estreiam nas salas de cinema, é um produto da cultura de massa, que segue padrões industriais (tempo de duração, janela de projeção, qualidade de som etc.) e precisa atender a uma grande quantidade de público para movimentar a indústria à qual a obra pertence.

A cultura de massa é um dos eixos do pensamento de Morin. O autor não inferioriza a cultura de massa, tomando-a como fútil ou menor que outras formas de expressão artística. Ao contrário de boa parte dos intelectuais ao seu redor, Morin (2018, p. XXVIII) se autointitula um apreciador do cinema, sem qualquer repulsa pela cultura de massa. Reconhece o caráter industrial, coletivo, técnico e padronizado dos estúdios de Hollywood, mas também o local em que nasceram obras-primas cinematográficas, que agregavam elementos originais e únicos, mesmo dentro da grande estrutura mercadológica que são os estúdios localizados em Los Angeles.

Morin reconhece que há inúmeras definições para o termo "cultura", desde a que deriva das ciências biológicas até os mais complexos estudos antropológicos, sociológicos e filosóficos. Em âmbito geral, para ele a cultura orienta ou inibe as ações humanas em qualquer sociedade; "é um corpo complexo de normas, símbolos, mitos e imagens que penetram o indivíduo em sua intimidade, estruturam os instintos, orientam as emoções" (MORIN, 2018, p. 5). O estudioso centra suas análises especificamente na cultura de massa que, segundo ele. foi detectada por sociólogos norte-americanos a partir da Segunda Guerra Mundial e constitui os produtos feitos segundo a lógica industrial, derivados da imprensa, do cinema, do rádio, da televisão etc., visando ao lucro (MORIN, 2018, p. 4).

Da mesma forma que Morin especifica o seu campo de análise da cultura, ou seja, a cultura de massa, antes de apresentar o conceito de poder cultural neste artigo também é preciso delimitar o que se entende por cultura. Trabalhar-se-á o termo "cultura" como sendo toda produção artística e de entretenimento produzida e circundada pelos meios de comunicação de massa e objetos da cobertura jornalística dos cadernos, portais de internet e revistas culturais no mundo, manifestada na forma de músicas, filmes, espetáculos teatrais, livros, programas de TV, artes visuais (instalações, plásticas, fotográficas e arte contemporânea).

O poder cultural é aquele exercido por artistas ou produtores de obras nos formatos anteriormente descritos. Mas nem toda obra gera poder cultural para seu respectivo artista ou produtor. 
Antes de compreender como a cultura gera poder, é preciso delinear o próprio termo "poder cultural". Aqui, ele é fruto da intersecção de dois conceitos notórios de poder, sendo o primeiro o chamado "poder simbólico", do sociólogo francês Pierre Bourdieu (2011). Para este, poder simbólico constitui-se do dado pela enunciação, faz ver e faz crer, confirma e transforma a visão de mundo e, também, o próprio mundo.

Bourdieu (2011, p. 11) afirma: "o que faz o poder das palavras e das palavras de ordem, poder de manter a ordem ou de a subverter, é a crença na legitimidade das palavras e daqueles que as pronunciam, crença cuja produção não é da competência das palavras".

Para Bourdieu (2011), o poder só é exercido mediante a cumplicidade dos que estão sujeitos a ele. A título de exemplo, o cineasta brasileiro Kleber Mendonça Filho ganhou as manchetes dos mais importantes jornais e canais de TV do mundo em maio de 2016, quando ele e a equipe do seu filme Aquarius protestaram, no tapete vermelho do Festival de Cannes, com cartazes que diziam que o Brasil estava sofrendo um golpe de Estado, em referência ao processo de impeachment da então presidente Dilma Rousseff (EQUIPE..., 2016). O diretor só ganhou tamanho destaque porque possui poder simbólico, tem legitimidade e também dá legitimidade às palavras que pronuncia. Muitos, certamente, concordaram ou passaram a concordar com o protesto de Mendonça Filho, não necessariamente pelas palavras escritas naquelas folhas de papel, mas pelo poder simbólico exercido por quem as segurava, poder esse adquirido, em parte, porque o filme Aquarius participava do Festival de Cannes, um dos festivais cinematográficos de maior legitimidade no mundo.

O segundo conceito de poder que constituirá o termo "poder cultural" é oriundo do cientista político norte-americano Joseph Nye (2004). Ao final dos anos 1980, quando a Guerra Fria dava sinais de esgotamento do modelo soviético, Nye cunhou o termo "poder suave" (soft powver), como:

[...] a habilidade de conseguir o que se quer por meio da atração, em vez de coerção e pagamentos. Surge da atratividade de um país por meio de sua cultura, ideia, políticos e políticas. [...] Quando você consegue que os outros admirem seus ideais e queiram o que você quer, você não precisa mais gastar muito em políticas de incentivo e sanções para movê-los em sua direção. (NYE, 2004, p. X, tradução nossa ${ }^{1}$ )

Também a título de exemplo, os norte-americanos foram hábeis em "vender" seu estilo de vida - o chamado American way of life - ao longo do século XX, não porque o impuseram por meio de sanções ou transações comerciais. Os produtos e os hábitos norte-americanos seduziram o mundo principalmente porque foram sutil e inteligentemente utilizados em filmes de Hollywood.

\footnotetext{
${ }^{1}$ - It's the ability to get what you want through attraction rather than coercion or payments. It arises from the attractiveness of a country's culture, political ideas, and policies. [...] When you can get other to admire your ideals and to want what you want, you do not have to spend as much on sticks and carrots to move them in your direction.
} 
Desde os anos 1920, quando os estúdios se formaram e passaram a dominar, paulatinamente, a bilheteria de grande parte dos países do mundo, as ideias, os valores (democracia, liberdade), bem como os produtos (máquinas de lavar, cigarros, refrigerantes, bonecos, jogos) foram fortemente impulsionados para o planeta, graças ao poder de sedução não desses produtos, mas dos filmes que os mostravam. Hollywood, portanto, possui poder suave.

Embora Nye trabalhe com o poder suave oriundo de diversos campos, como ciência, língua, religião, cultura e diplomacia, o foco aqui é o poder suave decorrente exclusivamente da cultura, cuja definição já foi anteriormente apresentada: na forma de produtos (livros, música, filmes) que circulam nos meios de comunicação de massa e são objeto da cobertura de jornais, revistas e portais de internet no mundo todo.

Em Poder suave, Franthiesco Ballerini (2017) enumera as manifestações culturais que possuem tal poder, sendo, portanto, hábeis em seduzir o mundo e produzir dividendos às instituições ou países que as produzem. São elas: Hollywood, Bollywood (o cinema indiano), a moda francesa, o balé russo, a arte milenar chinesa, as telenovelas brasileiras (TV Globo), a arte africana, a bossa nova, o carnaval brasileiro, a arte renascentista, a British Invasion (rock britânico, a partir dos Beatles, que invadiu o mercado dos Estados Unidos nos anos 1960) e a cultura MAG (mangá, animê e games) do Japão.

Tomando este último como exemplo, o próprio Nye (2004) reconhece, ainda que não seja seu foco de pesquisa, que a cultura MAG possui poder suave incontestável, com imagens japonesas dominando os sonhos de crianças há anos com sua mistura de "fofura" e poder, desenhos do Pokemón exibidos em 65 países e animações japonesas de sucesso entre produtores e adolescentes norte-americanos.

Já o carnaval brasileiro - especificamente o da Sapucaí, do Anhembi e de Barra-Ondina é exibido, há anos, em uma das maiores emissoras do mundo, a TV Globo, que, por sua vez, vende os direitos de exibição para diversos países. Essas manifestações carnavalescas não só seduzem os brasileiros como trazem bens tangíveis imensos ao turismo no Brasil, além de bens intangíveis como o imaginário da maior festa do mundo, fruto da alegria do povo brasileiro, entre outros.

Em comum, a cultura MAG japonesa e o carnaval brasileiro são poderes suaves estabelecidos porque seduzem populações em âmbito internacional há décadas. É o caráter da internacionalização que torna tais manifestações detentoras de poder suave. Portanto, o poder suave é exercido por instituições, países ou movimentos artísticos (British Invasion, bossa nova), enquanto o poder simbólico é exercido, dentro ou fora de um país, por indivíduos, por meio de suas produções de arte e entretenimento. 
O poder cultural é fruto da intersecção necessária e incondicional do poder simbólico com o poder suave. Assim, pode-se dizer que Mendonça Filho, embora tenha ganhado manchete em jornais do mundo inteiro com seu protesto em Cannes em 2016, não possui poder cultural. Isso porque o cinema brasileiro não possui poder suave, ou seja, não é um poder de âmbito internacional, que seduz plateias há décadas e traz dividendos contínuos e significativos ao Brasil, ao contrário das telenovelas da TV Globo, exportadas para mais de 80 países (GLOBO..., 2004) e que já foram capazes de fazer com que um mercado de rua em Luanda, Angola, fosse chamado de Roque Santeiro, por conta do êxito da novela brasileira naquele país. Da mesma forma, o restaurante denominado Paladar, da novela V ale Tudo, tornou-se também nome de alguns restaurantes privados, autorizados a funcionar em Cuba a partir dos anos 1990.

Então, Mendonça Filho possui poder simbólico dentro do campo do cinema em seu país, Brasil, com manifestações esporádicas no exterior, como no caso de Cannes. Já, Oprah Winfrey, Ashley Judd, Mira Sorvino e Geena Davis, por exemplo, possuem poder cultural. No início de 2018, elas utilizaram o poder suave de Hollywood - especificamente via Globo de Ouro e Oscar para amplificar, no mundo inteiro, o movimento \#MeToo, que havia começado em 2017, com denúncias de assédio sexual contra poderosos como o produtor de cinema Harvey Weinstein. Justamente pelo fato de estarem inseridas dentro de um sistema de poder suave estabelecido como Hollywood e terem, elas mesmas, poder simbólico notório, por meio de seus filmes e programas de TV, essas atrizes foram cruciais, a partir dos protestos, das palavras de ordem e do figurino preto utilizados nos festivais, para que o movimento tivesse muito mais do que apenas destaque em páginas de jornais. O poder cultural dessas mulheres foi fundamental para o peso do movimento, que, após esses festivais, repercutiu no mundo inteiro.

A empresa brasileira Natura lançou, em 2018, a campanha "Sororidade: todas juntas pelo fim da rivalidade feminina", inspirada no \#MeToo (SORORIDADE..., 2018). O diretor polonês Roman Polanski foi expulso da Academia, do Oscar, por ferir os termos de conduta da instituição, uma vez que é acusado de estupro de uma garota de 13 anos em 1977. Diversos sindicatos do Reino Unido colocaram cláusulas antiassédio nos contratos de emprego como resultado do \#MeToo a partir de 2019. O movimento deu legitimidade aos protestos contra o egípcio Ahmed Bassem Zaki, acusado em 2020 de ser predador sexual por diversas mulheres (CASO..., 2020). Na China, onde a liberdade de expressão não existe, a estudante Luo Qianqian foi a primeira mulher a se unir à campanha \#Me'Too e conseguir a demissão do professor Chen Xiaowu, que a assediou, em 2018 (PROFESSOR..., 2018). No Brasil, o movimento \#MeToo incentivou outro, o \#Exposed, que gerou a demissão de diversos professores em escolas públicas e particulares no ano de 2020, também em decorrência de acusações de assédio sexual. 
É improvável que o movimento \#MeToo tivesse tamanha repercussão e consequências sociais no mundo se personalidades detentoras de grande poder cultural não tivessem impulsionado o movimento em 2018. Essa é a manifestação mais concreta do alcance do poder cultural no século XXI.

No primeiro texto do livro Cultura de massas no século XX - o espirito do tempo: neurose e necrose, de Morin, Macé defende aquele autor da crítica feita por Bourdieu e Jean-Claude Passeron de que a obra de Morin se refere a uma cultura de massa "hegemônica e encantada que se tornaria - na esteira da teoria crítica da Escola de Frankfurt - um imaginário das massas, desprezando a diversidade e a complexidade dos usos, das práticas culturais e dos contextos de recepção" (MACÉ, 2018, p. XX). É interessante notar, também, nas mais de 20 páginas de referências bibliográficas do livro de Morin, que não há nenhuma menção a obras de Bourdieu.

Apesar de os próprios autores não explicitarem as suas concordâncias, são claras as aproximações entre os pensamentos de Bourdieu e Morin quando o campo é a cultura e o assunto é o poder dela emanado.

Em alguns poucos momentos, Morin utiliza-se do termo "poder cultural", entre aspas, como quando diz que:

[...] "o poder cultural", aquele do autor da canção, do artigo, do projeto de filme, da ideia radiofônica, se encontra imprensado entre o poder burocrático e o poder técnico [...] donde a tendência à despersonalização da criação, à predominância da organização racional de produção (técnica, comercial, política) sobre a invenção, à desintegração do poder cultural. (MORIN, 2018, p. 15)

No entanto, os termos são usados em contextos distintos do objeto proposto neste artigo.

Amante do cinema, Morin deixa evidente o poder de Hollywood no imaginário mundial, poder este que é capaz de fazer o público simpatizar com criminosos (Marlon Brando e $\mathrm{Al}$ Pacino em O poderoso chefão) e vagabundos (Charles Chaplin e seu Carlitos), enquanto, na vida real, os gangsters são vistos apenas como criminosos e desviamos quando um vagabundo nos pede esmolas. Morin questiona: como é possível que produtos de cultura de massa feitos nos Estados Unidos, carregados de marcas singulares de sua sociedade naquele momento, "tenham tido alcance e um sucesso universais?” (MORIN, 2018, p. XXXI).

A cultura de massa não tem pudores nem preocupações em misturar elementos eruditos, intelectuais ou populares dentro de um mesmo produto. Como lembra Morin (2018, p. 8):

[...] os jukebox oferecem ao mesmo tempo Armstrong e Brenda Lee, Brassens e Dalila, as lenga-lengas e a melodia [...]. O produto cultural está estritamente determinado por seu caráter industrial, de um lado, seu caráter de consumação diária, de outro, sem poder emergir para a autonomia estética. Ele não é policiado, nem filtrado, nem estruturado pela arte, valor supremo da cultura dos cultos. 
Na lógica desta mistura despreocupada dos elementos anteriormente citados, podese notar o poder cultural, por exemplo, da atriz israelense Natalie Portman. Para compreender o seu poder é preciso seguir uma linha de raciocínio. O lago dos cisnes é o balé mais visto de todos os tempos (BIDERMAN, 2017), obra erudita de quase 150 anos, primeiro espetáculo do Teatro Bolshoi, em Moscou, com música composta por Tchaikovsky. Ajudou a tornar o balé russo um dos poderes suaves culturais do planeta no século XX, lotando apresentações por onde passava no mundo inteiro. Mas o poder suave do balé russo nunca foi tão grande quanto o poder suave de Hollywood. Em 2010, Natalie Portman foi escolhida protagonista do filme Cisne negro. A obra, do estúdio hollywoodiano Fox, ganhou 93 prêmios e 141 indicações, segundo o site IMDb. Natalie Portman ganhou o prêmio mais desejado da indústria cinematográfica: o Oscar de Melhor Atriz. Em 2012, ela se casou com o bailarino francês Benjamin Millepied, que foi coreógrafo do filme Cisne negro. Eis que, em 2013, Millepied foi convidado para se tornar o diretor de dança do Ballet da Ópera de Paris, uma das mais prestigiosas companhias de dança do mundo e que teve como diretor o bailarino russo Rudolf Nureyev, morto em 1993 (MARIDO..., 2013). De brinde, ainda virou garoto propaganda da fragrância masculina L'Homme Libre, da Yves Saint Laurent, e da companhia aérea Air France. Teria Benjamin Millepied ganhado o posto de diretor tivesse Cisne negro sido um filme brasileiro ou argentino? Teria ele sido convidado para o cargo se Natalie Portman não fosse a atriz de seu filme e ganhado o Oscar?

A indústria cultural não é de natureza exclusivamente capitalista e privada. Mas Morin (2018) lembra que o "sistema de Estado" usa a cultura para fins de interesse político e ideológico, enquanto o "sistema privado" quer agradar o consumidor. "O sistema de Estado quer convencer, educar: por um lado, tende a propagar uma ideologia que pode aborrecer ou irritar; por outro, não é estimulado pelo lucro e pode propor valores de 'alta cultura' (palestras científicas, música erudita, obras clássicas)" (MORIN, 2018, p. 13).

O pensamento de Morin tem como contexto o século XX, marcado pela dualidade entre o modelo dos Estados Unidos e o da União Soviética. A Guerra Fria, porém, acabou no final dos anos 1980. Ainda assim, é possível validar o raciocínio do autor no contexto das relações políticas e culturais no século XXI. Rússia e China são países com presença de práticas capitalistas, mas em ambos os casos a mão do Estado é muito presente nas indústrias culturais domésticas. Nye (2013) chegou a escrever um artigo sobre o assunto: "O que a Rússia e a China não entendem sobre soft power", afirmando que Pequim e Moscou tentam colocar as mãos em suas atrações culturais “e falham miseravelmente". A China possui uma arte milenar com poder suave notório, ambicionado por museus e colecionadores do mundo inteiro. Dela, alguns artistas que assinaram as obras mais famosas tiveram invejável poder cultural, como Dong Yuan, cujas pinturas foram referência por 
mais de 900 anos. Mas a China sabe que, a partir do século XX, a arte de gravuras, pinturas e esculturas possui um poder suave cada vez mais limitado diante do poder das manifestações audiovisuais, desde o nascimento do cinema, seguido pela televisão e a internet. Por isso, o país tem feito, há anos, investimentos bilionários em sua indústria cinematográfica para tentar competir com Hollywood (FUNNEL, 2015). No entanto, são tantas as restrições e interferências do governo russo ao Balé Bolshoi e do governo chinês à indústria cinematográfica que temos grande dificuldade em elencar nomes de artistas de ambos os países com poder cultural.

Isso não quer dizer que sempre foi assim, ou seja, que a mão pesada do Estado inibiu o surgimento de artistas com poder cultural. Um exemplo vem da arte renascentista: manifestações de pintura, escultura, arquitetura e decoração nascidas em cidades italianas a partir de 1400 e que se tornaram o poder suave mais importante da Itália - que, à época, nem mesmo era um país, mas sim, inúmeros reinos localizados onde hoje está o país. A arte renascentista é fruto da aliança com o poder da Igreja, que naquele momento era também poder político. Os artistas trabalhavam sob encomenda e produziam aquilo que agradava à Igreja, sob o seu controle. Ainda assim, é impossível negar o poder cultural, até hoje, de nomes como Michelangelo, Leonardo Da Vinci, Rafael.

A receita da "cultura industrial", segundo Morin, é transformar temas locais em temas cosmopolitas, favorecendo sincretismos culturais e coproduções e, "por outro lado, os temas 'antropológicos', isto é, adaptados a um denominador comum de humanidade” (MORIN, 2018, p. 34). Essa talvez seja a receita fundamental para o surgimento de artistas com poder cultural. Afinal, de onde vem o poder cultural de João Gilberto e Tom Jobim, dois dos artistas da bossa nova com poder suave musical brasileiro? De uma mistura do local - a originalidade do ritmo, por sua vez uma mistura de samba, ritmos africanos e jazz - com temas cosmopolitas: a beleza da mulher (Garota de Ipanema), a saudade (Chega de saudade), a natureza (Samba do avião). O poder suave da bossa nova foi tão grande que mudou, inclusive, a imagem do Brasil e do brasileiro mundo afora.

Com seu notório estilo jocoso, afirma o músico Tom Zé:

\begin{abstract}
A Bossa Nova mudou a configuração do homem brasileiro, que era todo pé-duro, todo durão. Ela veio com tudo feminino... sendo feminino e frágil, foi o general que conquistou mais terras que Napoleão Bonaparte e Nabucodonosor. Foi essa coisa feminina e fraca que conquistou a América, a Europa e pariu o Brasil. O Brasil passou a existir depois da Bossa Nova. Antes dela, era um pedaço de terra amarela lá embaixo do mapa-múndi de que ninguém sabia. (VILELA, 2016)
\end{abstract}

O mesmo se pode dizer de Carlos Gardel e Astor Piazzolla, detentores de um poder cultural graças a esta mistura de elementos locais - o ritmo do tango, único e inconfundível, cartão postal, turístico e econômico da Argentina - com as letras cosmopolitas de suas músicas - o amor, a paixão, a dor, a saudade, sendo tão tocado e reproduzido no mundo que foi abocanhado diversas 
vezes pelo maior poder suave do mundo: Hollywood, em filmes como Luzes de Buenos Aires (1931), O tango da Broadway, (1934), Tango bar (1935) e o mais notório de todos, Perfume de mulher (1992), uma história de amor e superação (cosmopolita) ao som de tango (local).

Não se pode criticar Morin por ter uma visão lúdica, otimista ou "encantada" da cultura de massa, de seus artistas e produtores culturais. Se isso ainda não ficou claro, seu tom crítico fica evidente no texto Os olimpianos, que também possui fortes conexões com o conceito de poder cultural aqui trabalhado. Tomemos como exemplo um de seus pensamentos mais conhecidos sobre o tema.

\begin{abstract}
Esses olimpianos não são apenas os astros de cinema, mas também os campeões, príncipes, reis, playboys, exploradores, artistas célebres, Picasso, Cocteau, Dalí, Sagan. [...] Margaret e BB, Soraya e Liz Taylor, a princesa e a estrela se encontram no Olimpo da notícia dos jornais, dos coquetéis, recepções, Capri, Canárias e outras moradas encantadas. [...] A informação transforma esses olimpos em vedetes da atualidade. Ela eleva à dignidade de acontecimentos históricos acontecimentos destituídos de qualquer significação política, como as ligações de Soraya e Margaret, os casamentos ou divórcios de Marilyn Monroe ou Liz Taylor, os partos de Gina Lollobrigida, Brigitte Bardot, Farah Diba ou Elizabeth da Inglaterra. (MORIN, 2018, p. 99-100).
\end{abstract}

Os olimpianos de Morin são, também, os detentores de poder cultural advindos de Hollywood, das telenovelas brasileiras, de Bollywood, entre outros sistemas de poder suave estabelecidos. E, na lógica da venda e do consumo rápido, da despreocupação com erudição ou popularesco, estes olimpianos tomam as páginas de revistas, os telejornais e ganham a atenção mundial com acontecimentos destituídos de qualquer importância cultural, mas dignos de holofotes justamente pelo poder cultural que possuem.

Dessa forma, não só revistas de fofoca, mas respeitados veículos de comunicação do mundo inteiro se juntaram para descobrir por que o casamento da atriz Jennifer Aniston com o galã Brad Pitt não deu certo. "Jennifer Aniston e Brad Pitt estão cumprindo quarentena juntinhos? Aos fatos!” (JENNIFER..., 2020), "Brad Pitt explica porque traiu Jennifer Aniston com Angelina Jolie” (BRAD..., 2020), "Por dentro da mansão de 35 milhões de libras de Jennifer Anniston e Brad Pitt, com cinema e 13 banheiros" (TWIGGER, 2020), "Jennifer Aniston guarda o anel de noivado de Brad Pitt?” (JENNIFER..., 2020). São centenas de notícias como essas, com destaque e índices de leitura altíssimos na imprensa do mundo inteiro, que, para Morin (2018), são eficientes porque projetam no público um misto de proximidade e identificação. São olimpianos, mas com problemas humanos como todos nós.

O mesmo ocorre no Brasil, ainda que em âmbito menor, como consequência do poder suave das telenovelas brasileiras, especialmente da TV Globo. Seus astros e estrelas são lidos e assistidos não só pelos produtos que fazem, mas por suas vidas pessoais. "Reynaldo Gianecchini 
revela se traía Marília Gabriela" (PELÁJJIO, 2020), "Reynaldo Gianecchini se assume, desvenda mistério de relação com filho de Marília Gabriela e parte coração de galã” (TURA, 2019).

$\mathrm{Na}$ Índia, onde Bollywood se tornou um poder suave que seduz centenas de milhões de espectadores, é possível ver aquilo que Morin (2018, p. 101) descreve como uma mistura de "sua dupla natureza, divina e humana". No país, os atores e atrizes são venerados até com estátuas e recebem perdões incondicionais do público. Amitabh Bachchan, uma espécie de Al Pacino indiano, fez uma dezena de filmes e se tornou o ator mais importante do país. Em 1984, saiu da vida artística e foi eleito primeiro-ministro da Índia. Ele não terminou seu mandato porque se viu envolvido em um dos maiores escândalos de corrupção e lavagem de dinheiro do país, com subornos na compra de armas suecas. Foi preso? Esquecido? Não. Voltou aos cinemas e fez filmes que renderam mais de 50 milhões de rúpias. O poder cultural dos astros indianos reflete, também, no poder econômicos deles. Em 2014, o astro Shahrukh Khan era o segundo ator mais rico do mundo (FE ONLINE, 2014), com fortuna estimada em US $\$ 600$ milhões, atrás apenas de Jerry Seinfeld (US\$ 820 milhões) e à frente de Tom Cruise (US\$ 480 milhões).

Não é à toa que Morin abre seu texto com a famosa frase atribuída a B Rosenberg e D. Manning White: "É provável que, em média, o conhecimento dos americanos a respeito das vidas, dos amores e neuroses dos semideuses e deusas que vivem nas alturas olimpianas de Beverly Hills ultrapasse de muito seus conhecimentos dos negócios cívicos” (MORIN, 2018, p. 99).

No século XXI, o poder cultural destes olimpianos é ainda mais evidente quando eles possuem milhões de seguidores em suas contas no Instagram, atraem milhares de curtidas e comentários em fotos que revelam o canto do quarto, o despenteado do filho antes de ir pra escola, a saída do armário, assumindo um relacionamento homossexual, o abraço à causa de alguma minoria ou à nova dieta do momento ou até a briga dos filhos pela herança do pai da bossa nova, João Gilberto. Em suma, não é preciso ter poder cultural para inundar as páginas de fofocas, mas quando esses artistas fazem parte de poderes suaves estabelecidos, como Hollywood, a bossa nova, as telenovelas brasileiras, Bollywood e a British Invasion (o divórcio milionário de Paul McCartney), a amplitude dessas notícias sem qualquer importância cultural ganha um alcance inimaginável.

\section{Considerações finais}

É possível afirmar que, em comum, Pierre Bourdieu e Edgar Morin tiveram em seus livros, artigos e palestras uma preocupação preponderante com a educação. Este artigo compartilha da mesma preocupação dos sociólogos franceses.

O cinema, por exemplo, pode ser considerado importante ferramenta metodológica no processo educacional, tanto na educação básica quanto no ensino superior. O filme é um modo de 
expressar a realidade, cuja representação está no imaginário das pessoas; por isso, trata-se de uma linguagem de fácil compreensão, capaz de promover a discussão em torno de sérios e graves problemas sociais com situações do cotidiano. Um filme pode nos fazer refletir e até mudar de opinião ou comportamento. Entendemos também que, na escola, o cinema pode ser tratado como meio de lazer com conhecimento. O conteúdo fílmico pode ser explorado para a reflexão e a análise de temas transversais, históricos, das ciências em geral e contemporâneos.

O poder cultural é uma construção lenta, dependente de muitas variáveis, sendo, talvez, a principal, os hábitos de consumo de arte e entretenimento das sociedades. É provável que muitos espectadores considerem seu astro ou estrela poderosos e influentes por conta dos filmes ou do próprio talento artístico. Mas, como se pode ver neste artigo, são muitas as variáveis na consolidação do poder cultural de um artista ou produtor, e nem sempre é o produto do artista o elemento mais relevante nesta equação.

Ter consciência destes mecanismos que constroem, mantêm ou desagregam o poder cultural é o passo fundamental para mudar a lógica, quase sempre perversa, que beneficia os mesmos poucos em detrimentos do silêncio artístico de muitos. Quando consumimos um bom filme brasileiro, um bom programa de TV alemão, uma peça teatral inteligente do México, uma exposição belíssima de um artista nigeriano ou uma história inesquecível de um livro vietnamita, nos damos conta de quantos talentos e quantas manifestações culturais possuem pouca reverberação em âmbito mundial. Não possuem poder, mas "apenas" qualidade artística. Ter consciência da lógica da construção do poder cultural é, portanto, o primeiro passo para alterar a própria lógica. E isso tem tudo a ver com educação.

\section{Referências}

BALLERINI, Franthiesco. Poder suave. São Paulo: Summus, 2017.

BIDERMAN, Iara. Balé mais visto de todos os tempos, "Lago dos Cisnes" une erudito e pop. Folha de S. Paulo, São Paulo, 3 nov. 2017. Disponível em: https://www1.folha.uol.com.br/ilustrissima/2017/11/1932323-bale-mais-visto-de-todos-os-tempos-lago-dos-cisnes-une-erudito-epop.shtml. Acesso em: 16 jul. 2020.

BOURDIEU, Pierre. O poder simbólico. Lisboa, Edições 70: 2011.

BRAD Pitt explica porque traiu Jennifer Aniston com Angelina Jolie... e ainda garante que não se arrepende. Flash, Lisboa, 4 jun. 2020. Disponível em: https://www.flash.pt/atualidade/mundo/detalhe/brad-pitt-explica-porque-traiu-jennifer-anistou-com-angelina-jolie-e-aindagarante-que-nao-se-arrepende. Acesso em: 16 jul. 2020. 
CASA de Pablo Neruda é um convite para ir até a cidade de Valparaíso. Correio Brasiliense, Brasília, DF, 2 jan. 2017. Disponível em: https://www.correiobraziliense.com.br/app/noticia/turismo/2017/01/02/interna_turismo,562839/casa-de-pablo-neruda-e-um-convite-para-ir-ate-acidade-de-valparaiso.shtml. Acesso em: 16 jul. 2020.

CASO de predador sexual reforça movimento \#Me'Too no Egito. IstoÉ, São Paulo, 16 jul. 2020. Disponível em: https://istoe.com.br/caso-de-predador-sexual-reforca-movimento-metoo-noegito/. Acesso em: 16 jul. 2020.

EQUIPE de “Aquarius", de Kleber Mendonça Filho protesta em Cannes. El País, São Paulo, 19 maio 2016. Disponível em: https://brasil.elpais.com/brasil/2016/05/17/cultura/1463498064_139719.html. Acesso em: 16 jul. 2020.

FE ONLINE. Shah Rukh Khan beats Tom Cruise in Hollywood \& Bollywood rich list. Financial Express, Nova Déli, 22 maio 2014. Disponível em: https://www.financialexpress.com/archive/shah-rukh-khan-beats-tom-cruise-in-hollywood-bollywood-rich-list/1253019/. Acesso em: 21 abr. 2021.

FUNNELL, Antony. China pushes to expand its soft power through cultural exports. $A B C$, Londres, 6 maio 2015. Disponível em: https://www.abc.net.au/radionational/programs/futuretense/soft-power-with-chinese-characteristics/6446990. Acesso em: 16 jul. 2020.

GLOBO exporta para mais de 80 países. Agência Estado, São Paulo, 23 ago. 2004. Disponível em: https://cultura.estadao.com.br/noticias/geral,globo-exporta-para-mais-de-80-paises,20040823p6713. Acesso em: 20 jul. 2019.

JENNIFER Aniston e Brad Pitt estão cumprindo quarentena juntinhos? Aos fatos! Glamurama, São Paulo, 29 abr. 2020. Disponível em: https://glamurama.uol.com.br/jennifer-aniston-e-bradpitt-estao-cumprindo-quarentena-juntinhos-aos-fatos/. Acesso em: 16 jul. 2020.

JENNIFER Aniston guarda o anel de noivado de R \$2,5 milhões que ganhou de Brad Pitt? Rolling Stone, São Paulo, 16 de mai. 2020. Disponível em: https://rollingstone.uol.com.br/noticia/jennifer-aniston-guarda-o-anel-de-noivado-de-r-25-milhoes-que-ganhou-de-brad-pitt/. Acesso em: 16 jul. 2020.

MACÉ, Eric. Preâmbulo: a atualidade de O Espírito do Tempo. In: MORIN, Edgar. Cultura de massas no século XX. O espírito do tempo: neurose e necrose. 11. Ed. Rio de Janeiro: Forense, 2018.

MARIDO de Natalie Portman é o novo diretor do Ballet da Ópera de Paris. G1, São Paulo, 25 jan. 2013. Disponível em: http://g1.globo.com/pop-arte/noticia/2013/01/marido-de-natalieportman-e-o-novo-diretor-do-ballet-da-opera-de-paris.html. Acesso em: 16 jul. 2020.

MORIN, Edgar. Cultura de massas no século XX. O espírito do tempo: neurose e necrose. 11. ed. Rio de Janeiro: Forense, 2018.

MOURA, Carolina Silva de; ALMEIDA, Adrielly Campos e. Para além da doxa: caminhos metodológicos da Hermenêutica de Profundidade. Cadernos Unifoa, Volta Redonda, n. 34, p. 75-86, ago. 2017. 
NANAY, Bence. Ao triturar obra, Banksy aumentou seu valor em vez de destruí-la. Revista Época, Rio de Janeiro, 19 out. 2018. Disponível em: https:/ / epoca.globo.com/ao-triturar-obrabanksy-aumentou-seu-valor-em-vez-de-destrui-la-23168623. Acesso em: 16 jul. 2020.

NYE, Joseph. Soft power: the means to success in world politics. Nova York: Public Affairs, 2004.

NYE, Joseph. What China and Russia don't get about soft power. Foreign Policy, Londres, 29 abr. 2013. Disponível em: https://foreignpolicy.com/2013/04/29/what-china-and-russia-dont-getabout-soft-power/. Acesso em: 16 jul. 2020.

PROFESSOR é demitido na China após denúncia de assédio. Exame, São Paulo, 12 jan. 2018. Disponível em: https:/ / exame.com/mundo/professor-e-demitido-na-china-apos-denuncia-deassedio/. Acesso em 16 jul. 2020.

PELÁJJIO, Fhilipe. Reynaldo Gianecchini revela se traía Marília Gabriela com o filho dela. Uai, Belo Horizonte, 23 mar. 2020. Disponível em: https://lanoticia.uai.com.br/polemicas/reynaldogianecchini-revela-se-traia-marilia-gabriela-com-o-filho-dela-veja-aqui/. Acesso em: 16 jul. 2020.

SORORIDADE: todas juntas pelo fim da rivalidade feminina. Natura, São Paulo, 26 jun. 2018. Disponível em: https://www.natura.com.br/blog/mais-natura/sororidade-todas-juntas-pelo-fimda-rivalidade-feminina? cnddefault $=$ true\&raccoon_param1 $=$ institucional-conteudos\&raccoon_param2=sororidade\&gclid=Cj0KCQjw9b_4BRCMARIsADMUIyrn4v_Ld5nqAf0Q5r3Je2tNMPnFZeSolI16oQMm703Rw4uknU0LaQaAiSfEALw_wcB. Acesso em: 16 jul. 2020.

TURA, Aaron. Reynaldo Gianecchini se assume, desvenda mistério de relação com filho de Marília Gabriela e parte coração de galã. TV Foco, São Paulo, 10 out. 2019. Disponível em: https://www.otvfoco.com.br/reynaldo-gianecchini-se-assume-desvenda-misterio-de-relacaocom-filho-de-marilia-gabriela-e-parte-coracao-de-gala/. Acesso em: 16 jul. 2020.

TWIGGER, Will. Inside Jennifer Aniston and Brad Pitt's L35m marital home with cinema and 13 bathrooms. Mirror, Londres, 15 jul. 2020. Disponível em: https://www.mirror.co.uk/3am/celebrity-news/inside-jennifer-aniston-brad-pitts-22358261. Acesso em: 16 jul. 2020.

VILELA, Sávio. Primeira parte da entrevista exclusiva com Tom Zé. Carta Maior, São Paulo, 11 abr. 2016. Disponível em: https://www.cartamaior.com.br/?/Editoria/Midia/Primeira-parte-daentrevista-exclusiva-com-Tom-Ze/12/9546. Acesso em: 16 jul. 2020. 